\title{
Somatostatin Receptor in Human Hepatocellular Carcinomas: Biological, Patient and Tumor Characteristics
}

\author{
C. Verhoef ${ }^{a} \quad$ H. van Dekken ${ }^{b}$ L.J. Hofland ${ }^{c}$ P.E. Zondervan ${ }^{b} \quad$ J.H.W. de Wilt ${ }^{a}$ \\ R. van Marion ${ }^{b} \quad$ R.A. de Man ${ }^{d} \quad$ J.N.M. IJzermans ${ }^{a} \quad$ C.H.J. van Eijck ${ }^{a}$ \\ Departments of a Surgery, ${ }^{b}$ Pathology, ${ }^{\mathrm{C}}$ Internal Medicine, ${ }^{\mathrm{d}}$ Gastroenterology and Hepatology, \\ Erasmus Medical Centre, Rotterdam, The Netherlands
}

\section{Key Words}

Hepatocellular carcinoma · Somatostatin receptor •

Clinical characteristics $\cdot$ Genetic alterations

\begin{abstract}
Background/Aim: The evidence on the efficacy of somatostatin analogues in the treatment of hepatocellular carcinoma (HCC) in humans is conflicting. A variety of human tumors demonstrate somatostatin receptors. All subtypes bind human somatostatin with high affinity, while somatostatin analogues bind with high affinity to somatostatin receptor subtype 2 (sst2). We investigated the sst2 expression in HCC and examined whether HCCs expressing sst2 are a distinct subgroup. Patients and Methods: Forty-five human HCCs were tested for sst 2 expression and biological alterations. The proliferative capacity was determined with Ki67 immunostaining and the DNA ploidy status was measured by fluorescent in situ hybridization with a chromosome 1-specific repetitive DNA probe. Expression of tumor suppressor genes (p16, p53 and Rb1) was measured by immunohistochemistry. Results: sst2 expression was detected in 30 tumors (67\%). No correlation existed between sst2 ex-
\end{abstract}

\section{KARGER}

Fax +41613061234

E-Mail karger@karger.ch

www.karger.com
(C) 2008 S. Karger AG, Basel

$0253-4886 / 08 / 0251-0021 \$ 24.50 / 0$

Accessible online at:

www.karger.com/dsu pression and the immunoprofiles of the tumor suppressor genes, aneuploidy, proliferation, age, gender, $\alpha$-fetoprotein levels, tumor size, tumor grade and underlying liver disease. Conclusion: In $67 \%$ of the patients with HCC, sst 2 could be detected in the tumor. No clinical, pathological or biological characteristics were specific for sst2-positive tumors.

Copyright $\odot 2008$ S. Karger AG, Basel

\section{Introduction}

Hepatocellular carcinoma (HCC) is the most common primary liver cancer and fifth most common cancer in the world. Recent reports suggest an increase in the incidence of HCC in the Western World; however, this may reflect a referral bias $[1,2]$. Only a minority of patients can be treated by partial liver resection, liver transplantation or local treatment (radiofrequency, percutaneous ethanol injection, transarterial chemoembolization). Because HCC is not sensitive to systemic chemotherapy [3], other therapies are tried. Results of studies investigating the effect of somatostatin analogues on HCC in humans are conflicting [4-8]. Somatostatin receptors (SS-Rs) 
have been demonstrated in a variety of human tumors. At least 5 different human subtypes (SS-R subtype 1-5) have been cloned. All subtypes bind human somatostatin with high affinity, while somatostatin analogues bind with high affinity to SS-R subtype 2 (sst2). Literature data on the expression of SS-Rs in HCC are scarce. There is no study published, investigating whether HCC tumors expressing SS-Rs are a distinct subgroup at the genetic level. To investigate the SS-Rs in HCC and to test whether specific genetic alterations are associated with SS-Rspositive or SS-Rs-negative HCCs, we examined protein (over)expression of tumor suppressor genes (p16, p53 and Rbl) by immunohistochemistry. Further, the proliferative capacity was examined by immunostaining of Ki67 and DNA ploidy status (aneuploidy) was measured by fluorescent in situ hybridization (FISH) with a chromosome 1-specific repetitive DNA probe. Our results will indicate the existence of SS-Rs in human HCC, and we will describe whether there is a correlation between SS-Rs expression and clinical and pathological characteristics, or alterations of investigated proto-oncogenes.

\section{Material and Methods}

\section{Patient Material}

Tissue of surgically resected tumors of patients with HCC were analyzed in this study. The diagnosis was formulated according to the guidelines issued by the World Health Organization [9]. We collected representative paraffin blocks from neoplastic liver cell specimens. HCCs were graded using a standard grading system [10].

Tumor samples from surgical resections of 58 patients with HCC were selected for the tissue microarray (TMA). Of each resection specimen, $0.6-\mathrm{mm}$ tissue cylinders were punched out of the tissue blocks, and brought into the array block with regular spacing between the cylindrical biopsies. From each patient, 2 tissue cores were included in the TMA. A standard HE-stained histological section of the TMA was made for quality control. In 10 cases, no adequate carcinoma tissue cores were available for analysis due to absence or inadequate numbers of tumor cells. In 3 cases, SS-Rs could not be determined by technical errors. A total of 90 liver tissue samples were available for analysis, i.e. 45 HCCs.

\section{Fluorescent in situ Hybridization}

FISH was performed on a 4 - $\mu$ m-thick tissue section of the TMA that was adhered to an aminoacetylsilane (AAS)-coated slide (Starfrost, Berlin, Germany). The (peri)centromeric DNA probe for chromosome 1 was labeled with Spectrum Green using a Nick Translation Reagent Kit (Vysis, Downers Grove, Ill., USA) according to the manufacturer's directions. The FISH procedure was carried out basically as described before by us [11, 12]. Briefly, after appropriate pepsin digestion, sections were heat-denatured for $2 \mathrm{~min}$ in $70 \%$ formamide in $2 \times$ SSC, and hybridized overnight at $37^{\circ} \mathrm{C}$ with the denatured probes in a hybridization mixture containing $2 \mathrm{ng} / \mu \mathrm{l}$ DNA probe, $500 \mathrm{ng} / \mu \mathrm{l}$ herring sperm DNA (Sigma, St. Louis Mo., USA), 0.1\% Tween-20, 10\% dextran sulphate, and $60 \%$ formamide in $2 \times$ SSC at $\mathrm{pH}$ 7.0. Then, a series of stringent washes followed to remove unbound probe. Finally, the section was counterstained with DAPI in antifade solution (Vectashield; Vector, Burlingame, Calif., USA). The FISH results were analyzed on a computer screen. Images of each of the 2 fluorochromes were collected using an epifluorescence microscope (Leica DM, Rijswijk, The Netherlands) equipped with appropriate excitation and emission filter sets (Leica), and a cooled CCD camera (Photometrics, Tucson, Ariz., USA). The green and blue images were collected sequentially by changing the excitation filter using CW4000 FISH software (Leica). Two investigators scored a minimum of 50 interphase cell nuclei per tissue core, and the number of green fluorescent centromere 1 spots per nucleus was scored $(0,1,2,3,4,>4$ spots/nuclear slice). Then, the percentage of hyperdiploid cell nuclei was determined.

\section{Immunohistochemistry p16, p53, Rb1 and Ki67 Antigen}

The immunohistochemistry was carried out as described before by us [13]. Basically, 4- $\mu \mathrm{m}$ consecutive tissue sections of the TMA were mounted on AAS-coated slides (Starfrost, Berlin, Germany), and immunostaining was performed using the UltraVision Large Volume Detection System Anti-Polyvalent, HRP (Labvision, Fremont, Calif., USA). After deparaffinization, microwave $(700 \mathrm{~W})$ pretreatment was performed for $15 \mathrm{~min}$ using citrate buffer (10 mM citric acid monohydrate, $\mathrm{pH}$ 6.0). The p16 gene product was evaluated using antibody E6H4 (DAKO, Glostrup, Denmark), diluted $1 / 25$ in phosphate-buffered saline/5\% bovine serum albumin (BSA). To assess overexpression of the $\mathrm{p} 53$ protein, the primary antibody DO-7, recognizing both wild-type and mutant p53, (DAKO) was used, diluted 1/50 in phosphate-buffered saline/5\% BSA. The retinoblastoma gene product was evaluated with clone Rb1 (DAKO), diluted $1 / 25$ in phosphate-buffered saline $/ 5 \%$ BSA. This antibody reacts with the cell cycle-related phosphorylated form of $\mathrm{Rb}$ protein. To estimate proliferation rate, primary labeling of the Ki67 antigen was performed with antibody Mib-1 (Immunotech, Marseille, France), diluted 1/100 in phosphate buffered saline (PBS)/5\% BSA. As a positive control, a cytokeratin 8/18 antibody was used; as a negative control, the primary antibody was omitted. At least 50 cells were scored by two independent investigators. For Ki67, a percentage $>1 \%$ was regarded as increased proliferation. For p16, p53 and Rb1, an identical scoring system was used: a percentage exceeding $1 \%$ of positive cells was regarded as protein overexpression of these tumor suppressor genes. The cut-off value of $1 \%$ was based on immunostaining profiles of normal liver controls.

\section{SS-R Immunohistochemistry}

Five- $\mu \mathrm{m}$ sections of the TMA were mounted on AAS-coated slides (Starfrost, Berlin, Germany). Immunohistochemistry was performed as described previously [14]. Briefly, the slides were deparaffinized, dehydrated, exposed to microwave heating (in citric acid buffer, $10 \mathrm{~min}$ at $100^{\circ} \mathrm{C}$ ), rinsed in tap water and PBS and incubated for $15 \mathrm{~min}$ in normal goat serum (1:10 dilution in PBS $+5 \%$ BSA). Thereafter, the cells were incubated overnight at $4^{\circ} \mathrm{C}$ with antibody against sst $2 \mathrm{~A}$ (SS-800 antibody, Biotrend, Cologne, Germany). The primary antibody was used at a dilution of $1: 2,000$ in PBS + 5\% BSA. A standard streptavidin-biotinylated- 
Table 1. Clinical and pathological data from 45 patients with HCC

\begin{tabular}{lclll}
\hline & sst2+ & sst2- & Total & Difference \\
\hline Patients & $30(67)$ & $15(33)$ & $45(100)$ & \\
Age, years & $59(23-74)$ & $53(39-74)$ & $57(23-74)$ & NS \\
Male & $19(63)$ & $9(60)$ & $28(62)$ & NS \\
Female & $11(37)$ & $6(40)$ & $17(38)$ & \\
Tumor diameter, cm & $5(1-16)$ & $4(2-12)$ & $5(1-16)$ & NS \\
Grade I or II tumor & $19(63)$ & $9(60)$ & $28(62)$ & NS \\
Grade III tumor & $11(37)$ & $6(40)$ & $17(38)$ & \\
Underlying liver cirrhosis & $20(67)$ & $9(60)$ & $29(64)$ & NS \\
Without liver cirrhosis & $10(33)$ & $6(40)$ & $16(36)$ & \\
\hline
\end{tabular}

Figures in parentheses represent percentages or range. peroxidase complex (ABC) kit (Biogenix, San Ramon, Calif., USA) was used according to the manufacturers protocol to visualize the bound antibodies. Paraffin-embedded sections of normal human pancreas served as a positive control. Negative controls for immunohistochemistry included: (1) omission of the primary antibody, (2) preabsorption of the antibodies with immunizing peptide (at a concentration of $100 \mathrm{nM}$ ). A tissue was considered positive for sst $2 \mathrm{~A}$ when immunostaining was abolished by preabsorption with the immunizing peptide. Specificity of the SS- 800 sst $2 \mathrm{~A}$ antibody has been previously described in detail [15].

\section{Statistical Evaluation}

The Mann-Whitney U test was used for comparisons between the specimen groups for the percentage of hyperdiploid cell nuclei (aneuploidy). It was further used to evaluate the clinical parameter age and tumor size. Fisher's exact test was applied for comparisons of the immunostaining results between groups, as well as tumor grade in relation to FISH and immunostaining. Also the parameter gender was evaluated using this test. A p value of 0.05 (two sided) was taken as the limit of significance. A $p$ value between 0.05 and 0.10 was considered a statistical trend.

\section{Results}

\section{Patient Characteristics}

Twenty-eight men and 17 women were investigated with a median age of 57 years (23-74) and a median tumor size of $5 \mathrm{~cm}$ [1-16]. Twenty-nine patients (64\%) had underlying liver cirrhosis.

\section{Somatostatin Receptor 2 Expression}

Somatostatin receptor 2 expression was assessed by immunohistochemistry. In our series of 45 tumors, sst 2 expression was detected in 30 tumors (67\%). Patient and tumor characteristics compared with sst 2 status of the tumor are summarized in table 1. Age, gender, tumor size, tumor grade and underlying liver disease of the
Table 2. Genetic alterations in 45 HCCs in relation to sst 2 expression

\begin{tabular}{lrrrl}
\hline & sst2+ & \multicolumn{1}{c}{ sst2- } & Total & Difference \\
\hline Patients & $30(67)$ & $15(33)$ & \multicolumn{1}{l}{45} & \\
P16+ & $6(20)$ & $2(13)$ & $8(18)$ & NS \\
P16- & $24(80)$ & $13(87)$ & $37(82)$ & \\
P53+ & $15(50)$ & $8(53)$ & $23(51)$ & NS \\
P53- & $15(50)$ & $7(47)$ & $22(49)$ & \\
Rb1+ & $15(50)$ & $8(53)$ & $23(51)$ & NS \\
Rb 1- & $15(50)$ & $7(47)$ & $22(49)$ & \\
Ki67+ & $17(57)$ & $9(60)$ & $26(58)$ & NS \\
Ki 67- & $13(43)$ & $6(40)$ & $19(42)$ & \\
Aneuploidy & $33(8-70)$ & $19(10-66)$ & $28(8-70)$ & NS
\end{tabular}

Figures in parentheses represent percentages or range.

sst2+ tumors were not significantly different from the sst2- tumors.

\section{Genetic Alterations}

Protein (over)expression of tumor suppressor genes (p16, p53 and Rb1) was examined by immunohistochemistry. The proliferative capacity was examined by immunostaining of Ki67 and DNA ploidy status (aneuploidy) was measured by FISH with a chromosome 1specific repetitive DNA probe. The results are shown in table 2.

Aneuploidy, i.e. the percentage of hyperdiploid cells, was 33 (range 8-70) in the ssr2+ tumors versus 19 (range $10-66$ ) in the sst 2 - tumors (NS). No differences were observed between the sst2- and sst $2+$ tumors for $\mathrm{p} 53$, p16, $\mathrm{Rb} 1$ oncoprotein or proliferation markers. 
Table 3. Somatostatin receptors in patients with HCC

\begin{tabular}{lrll}
\hline & $\begin{array}{l}\text { Pa- } \\
\text { tients }\end{array}$ & $\begin{array}{l}\text { SST2 }+ \\
\text { (tumor), \% }\end{array}$ & Method \\
\hline Reubi et al. [22] & 59 & $41^{1}$ & autoradiography \\
Bläker et al. [21] & 56 & 41 & immunohistochemistry \\
Reynaert et al. [24] & 6 & 67 & immunohistochemistry \\
Erasmus M.C. & 45 & 67 & immunohistochemistry \\
\hline
\end{tabular}

${ }^{1}$ All ssr subtypes (1-5).

\section{Discussion}

In preclinical studies, somatostatin analogues (SS) inhibit the growth of a wide variety of tumors in vivo and in vitro [16-18]. The published studies regarding the efficacy of SS on survival in patients with HCC are conflicting. Some studies did not display an improvement in survival in patients with unresectable HCCs [4-6], while others found a significant survival benefit $[7,8,19]$. The placebo-controlled randomized trials did not show significant benefit of SS on patient survival $[4,20]$.

There is no explanation for these contradictory results. If one analyzes the number of studies regarding the efficacy of SS in the treatment of HCC, it is striking that studies investigating the SS-R in human HCC are limited. The variations in receptor expression may explain differences in clinical efficacy. To our knowledge, 3 studies described the expression of tumor ssr in patients with HCC (table 3). The studies of Bläker et al. [21] and Reubi et al. [22] studied the correlation between SS-Rs and tumor characteristics. Our study confirmed their results that there is no correlation between tumor stage, tumor differentiation and underlying liver disease. Moreover, there was no correlation between SS-Rs and age or gender. Therefore, it is not possible to predict the existence of SS-Rs in human HCC based on available clinical parameters. If the expression of SS-Rs in HCC plays a role in the outcome regarding SS treatment in patients with HCC, it is not possible to stratify the patients based on clinical characteristics.

It is known that there are 5 subtypes of SS-Rs. All SSRs [1-5] have been implicated in antiproliferative signaling [23]. Our study investigated the ssr2 and not the other subtypes SS-Rs 1,3-5. There is a difference in binding affinity between analogues of SS and the SS-Rs subtypes. Octreotide, an often used SS analogue, has a high binding affinity with sst2 compared to the other SS-R subtypes. The absence or presence of sst 2 subtype in HCC might be the cause of the divergent biological responses in trials with octreotide in patients with advanced HCC. This is one of the reasons we tested sst2 in human HCC. The most important decisive factor to test sst 2 is the fact that we examined the determination of SS-Rs subtypes with immunohistochemistry followed by a determination with PCR as the gold standard. The most reliable subtype determination was sst 2 and sst 3 (100\% score). Testing for the other subtypes is in our hands not reproducible. Because of the high affinity with SS analogues, we determined that sst 2 is the most clinical significant subtype. In our series, $67 \%$ of the HCCs expressed sst2, which is exactly the same percentage of sst 2 found in the study of Reynaert et al. [24] and higher than the $41 \%$ Bläker et al. [21] found. Because of the higher binding affinity of sst2 to SS analogues compared to the other SS-Rs subtypes and the variable ssrt 2 expression in HCC found in our study and others, clinical trials evaluating the treatment of SS analogues in patients with HCC, should take these findings into account.

SS-Rs may play a role in the progression of cancers. Binding studies suggested that SS-Rs were preferentially expressed in well-differentiated compared to less differentiated tumors $[25,26]$. In other words, SS-Rs may play a role in the differentiation in some cancers. Loss of SSRs expression in tumor cells would confer a proliferative advantage to those cells and their progeny. In regard of this point genes of the SS-Rs can be regarded as tumor suppressor genes. This suggestion is supported by the observation that a point mutation in sst2 gene results in a proliferative advantage in small cell lung cancer cells in vitro [27]. If SS-Rs can be regarded as tumor suppressor genes, it might be that SS-Rs+ subgroup is a distinct group of patients. Maybe specific genetic alterations are associated with SS-R-positive HCCs and this may be another possible explanation for the conflicting results regarding the effect of SS analogues on survival in patients with HCC.

The p53 oncosuppressor is the gene which has been found to be most frequently altered in human cancers. Moreover, it is the most commonly mutated gene in HCC [28-31]. In a large study of Qin et al. [31], nuclear staining for p53 was found in $50.5 \%$ of the cases (112 of the 222 cases). Some reports are indicating that p53 is an independent prognostic marker regarding survival [30, 31]. Among the known tumor suppressor genes, the inactivation of p16 is reported to be second only to p53 inactivation in human neoplasia [32]. Also in human HCC, p16 
is a major inactivation target [33, 34]. Edamoto et al. [35] recently demonstrated that alterations in the RB1 pathways commonly occur in HCCs. In a selected group of 45 patients, we investigated whether any of the genetic alterations that are frequently observed in HCCs (p53, p16 and RB1) were specific for the SS-R+ or SS-R- subgroups. None of the investigated oncogenes are specific for the subgroups.

\section{Conclusion}

In $67 \%$ of the patients with HCC, sst 2 could be detected in the tumor. No clinical characteristics were specific for sst2+ or sst2- tumors. There are no specific genetic alterations, aneuploidy or proliferation markers associated with sst2+ or sst2- HCCs.

\section{Acknowledgement}

The authors thank Mrs. A.M. Waaijers for performing the immunohistochemical analysis of sst 2 receptors.

\section{References}

-1 El-Serag H, Davilla JA, Petersen NJ, McGlynn KA: The continuing increase in the incidence of hepatocellular carcinoma in the United States: an update. Ann Intern Med 2003;139:817-823.

-2 Verhoef C, Visser O, de Man RA, de Wilt JHW, Ijzermans JNM, Janssen-Heijnen MLGl: HCC in the Netherlands: incidence treatment and survival patterns. EJC 2004; 40:1530-1538.

$>3$ Schwartz JD, Beutler AS: Therapy for unresectable hepatocellular carcinoma: review of the randomized clinical trials. II. systemic and local non-embolization-based therapies in unresectable and advanced hepatocellular carcinoma. Anticancer Drugs 2004;15:439452.

4 Yuen MF, Poon RT, Lai CL, et al: A randomized placebo-controlled study of long-acting octreotide for the treatment of advanced hepatocellular carcinoma. Hepatology 2003; 36:687-691.

5 Rabe C, Pilz T, Allgaier, et al: Clinical outcome of a cohort of 63 patients with hepatocellular carcinoma treated with octreotide. $\mathrm{Z}$ Gastroenterol 2002;40:395-400.

6 Raderer M, Hejna MH, Muller C, et al: Treatment of hepatocellular cancer with the long acting somatostatin analoglanreotide in vitro and in vivo. Int J Oncol 2000;16:11971201.

7 Dimitrouloupoulos D, Xinopoulos D, Tsamakidis $\mathrm{K}$, et al: The role of sandostatin LAR in treating patients with advanced hepatocellular cancer. Hepatogastroenterology 2002;49:1245-1250.

-8 Samonakis DN, Moschandreas J, Arnaoutis T, et al: Treatment of hepatocellular carcinoma with long acting somatostatin analogues. Oncol Rep 2002;9:903-907.

9 Gibson JB, Sobin LH: Histological typing of tumours of the liver, biliary tract and pancreas; in International Histological Classification of Tumours. Geneva, World Health Organisation, 1978.
10 Edmondson HA, Steiner PE: Primary carcinoma of the liver. A study of 100 cases among 48,900 necropsies. Cancer 1954;7:462-503.

11 Alers JC, Van Dekken H: Interphase cytogenetic analysis of solid tumors by non-isotopic DNA in situ hybridization. Progr Histochem 1996;31:1-137.

12 Van Dekken, Wink J, Alers JC, de Man RA, Ijzermans JN, Zondervan PE: Genetic evaluation of the dysplasia-carcinoma sequence in chronic viral liver disease: a detailed analysis of two cases and a review of the literature. Acta Histochem 2003:105:29-41.

13 Van Dekken H, Verhoef C, Wink J, van Marion R, Vissers KJ, Hop WC, de Man RA, Ijzermans JN, van Eijck CHJ, Zondervan PE: Cell biological evaluation of liver cell carcinoma, dysplasia and adenoma by tissue micro-array analysis. Acta Histochem 2005: 107:161-171.

14 Hofland L, et al: Immunohistochemical detection of somatostatin receptor subtypes sst1 and sst2A in human somatostatin receptor positive tumors. J Clin Endocrinol Metab 1999;84:775-780.

15 Korner M, et al: Value of immunohistochemistry for somatostatin receptor subtype sst2A in cancer tissues: lessons from the comparison of anti-sst2A antibodies with somatostatin receptor autoradiography. Am J Surg Pathol 2005;29:1642-1651.

16 Schally AV: Oncological applications of somatostatin analogues. Cancer Res 1988;48: 6977-6985.

17 Lamberts SW, Krenning EP, Reubi JC: The role of somatostatin and its analogs in the diagnosis and treatment of tumors. Endocr Rev 1991;12:450-482.

18 Weckbecker G, Raulf F, Stolz B, Bruns C: Somatostatin analogs for diagnosis and treatment of cancer. Pharmacol Ther 1993;60: 245-264.
9 Kouroumalis E, Skordilis P, Thermos K, Vasilaki A, Moschandrea J, Manousos ON: Treatment of hepatocellular carcinoma with octreotide: a randomised controlled study. Gut 1998;42:442-447.

20 Allgaier HP, Becker G, Olschewski M, et al: Octreotide treatment in patients with advanced hepatocellular carcinoma: first results of the randomized placebo-controlled double blind Hector trial. Hepatology 2003; 38:760A.

21 Bläker M, Schmitz M, Gocht A, et al: Differential expression of somatostatin receptor subtypes in hepatocellular carcinomas. J Hepatol 2004;41:112-118.

22 Reubi JC, Zimmerman A, Jonas S, Waser B, Neuhaus P, Laederach U, Wiedenmann B: Regulatory peptide receptors in human hepatocellular carcinomas. Gut 1999;45:766774.

23 Kumar U, Grigorakis SI, Watt HL, Sasi R, Snell L, Watson P, Chaudhari S: Somatostatin receptors in primary human breast cancer: quantitative analysis of mRNA for subtypes 1-5 and correlation with receptor protein expression and tumor pathology. Breast Cancer Res Treat 2005;92:175-186.

24 Reynaert H, Rombouts K, Vandermonde A, et al: Expression of somatostatin receptors in normal and cirrhotic human liver and in hepatocellular carcinoma. Gut 2004;53:11801189.

25 Reubi JC: Octreotide and nonendocrine tumors. Basic knowledge and therapeutic potential; in Lomax P, Scarpignato C, Vessel E (eds): Octreotide from Basic Science to Clinical Medicine. Basel, Karger, 1996, pp $246-$ 269.

26 Reubi JC, Laissue J, Krenning E, Lamberts SW: Somatostatin receptors in human cancer: incidence, characteristics, functional correlates and clinical implications. J Steroid Biochem Mol Biol 1992;43:27-35. 
27 Zhang CY, Yokogoshi Y, Yoshimoto K, Fujinaka Y, Matsumoto K, Saito S: Point mutation of the somatostatin receptor 2 gene in the human small cell lung cancer cell line COR-L103. Biochem Biophys Res Commun 1995;210:805-815.

$\checkmark 28$ Hsu HC, Tseng HJ, Lai PL, et al: Expression of p53 gene in 184 unifocal hepatocellular carcinomas: association with tumour growth and invasiveness. Cancer Res 1993;53:46914694

29 Hsu HC, Peng SY, Lai PL, et al: Mutations of p53 gene in hepatocellular carcinoma (HCC) correlate with tumor progression and patient prognosis: a study of 138 patients with unifocal HCC. Int J Oncol 1994;4:1341-1347.
30 Peng SY, Chen WJ, Lai PL, et al: High $\alpha$-fetoprotein level correlates with high stage, early recurrence and poor prognosis of hepatocellular carcinoma: significance of hepatitis virus infection, age, p53 and $\beta$-catenin. Int J Cancer 2004;112:44-50.

31 Qin LX, Tang ZY, Ma ZC, et al: p53 immunohistochemical scoring: an independent prognostic marker for patients after hepatocellular carcinoma resection. World J Gastroenterol 2002;8:459-463.

32 Sherr CJ: Cancer cell cycles. Science 1996; 274:1672-1677.
3 Baek MJ, Piao Z, Kim NG, et al: P16 is a major inactivation target in hepatocellular carcinoma. Cancer 2000;89:60-68.

34 Matsuda Y, Ichida T, Genda T, et al: Loss of p16 contributes to p27 sequestration by $\mathrm{cy}$ clin D1-cyclin-dependent kinase 4 complexes and poor prognosis in hepatocellular carcinoma. Clin Cancer Res 2003;9:3389-3396.

35 Edamoto Y, Hara A, Biernat W, et al: Alterations of RB1, p53 and Wnt pathways in hepatocellulular carcinomas associated with hepatitis C, hepatitis B and alcoholic liver cirrhosis. Int J Cancer 2003;106:334-341. 